\title{
Body composition in older acute stroke patients after treatment with individualized, nutritional supplementation while in hospital
}

\author{
Lisa $\mathrm{Ha}^{1 *}$, Truls Hauge ${ }^{2}$, Per Ole Iversen ${ }^{3,4}$
}

\begin{abstract}
Background: Individualized, nutritional support reduced undernutrition among older stroke patients and improved quality of life in our recent randomized, controlled trial. Weight control thus seems to be important after stroke, and methods for monitoring nutritional status need to be simple and non-invasive. Here we aimed to assess if the nutritional intervention altered body composition in men and women in this study cohort, and also to examine the correlation between the methods for assessing body-, fat- and fat-free mass.

Methods: Acute stroke patients $>65$ years at nutritional risk were randomized to either individualized, nutritional treatment with energy- and protein rich supplementation (intervention, $\mathrm{n}=58$ ) or routine, nutritional care (control, $n=66$ ) while in hospital. Body composition was assessed with anthropometry and bioelectrical impedance. The follow-up period was three months.
\end{abstract}

Results: During the first week while in hospital, weight loss was smaller in the intervention group compared with the controls $(P=0.013)$. After three months weight- and fat loss were significant in both men and women.

Whereas no significant differences were found in changes in body composition between the male study groups, in the women both weight loss $(P=0.022)$ and fat loss $(P=0.005)$ was smaller in the intervention group compared with the controls. A high correlation ( $r=0.87$ ) between mid upper arm circumference (MUAC) and body mass index (BMI) was found.

Conclusions: Individualized nutritional support to older stroke patients in hospital was beneficial for maintaining an adequate body mass and body composition the first week and seemed to have a preventive effect on fat loss among women, but not among men after three months. Measurement of MUAC may be used in the assessment of nutritional status when BMI cannot be obtained.

Trial registration: This trial is registered with ClinicalTrials.gov, number NCT00163007.

\section{Background}

In older persons, the presence of chronic diseases, polypharmacy, eating difficulties and various functional disabilities can result in inadequate dietary intake and malnutrition. Hence, protein- and energy undernutrition may be manifest or in progression when the older person is hospitalized for an acute stroke. Dysphagia or other feeding problems arising from neurological, cognitive or motoric impairments after stroke can give further

\footnotetext{
* Correspondence: lisaha@online.no

'Department of Internal Medicine, Østfold Hospital Trust Fredrikstad, 1603 Fredrikstad, Norway

Full list of author information is available at the end of the article
}

nutritional deterioration [1-4]. Prospective cohort studies have shown a decrease in body weight after acute stroke and a loss of muscle- and fat mass [5,6]. When signs of protein- and energy deficits are present in acute stroke patients, there is an increased risk of poor functional outcome, pneumonia and other infections, gastrointestinal bleeding, bedsores and higher mortality [1,2,7-10]. This could in turn increase hospital stay, decrease quality of life and impair rehabilitation outcome. Hence, the main purpose of nutritional treatment after an acute stroke is to prevent or treat complications from energy- and protein undernutrition [11]. However, the impact of nutritional supplementation on body
Ciomed Central

() $2010 \mathrm{Ha}$ et al; licensee BioMed Central Ltd. This is an Open Access article distributed under the terms of the Creative Commons Attribution License (http://creativecommons.org/licenses/by/2.0), which permits unrestricted use, distribution, and reproduction in any medium, provided the original work is properly cited. 
composition in elderly stroke patients is unclear. Randomized, controlled trials have not shown any differences in changes in body weight, triceps skinfold thickness or mid-upper arm circumference in stroke patients after supplementation with energy- and protein rich sip feedings compared to routine, nutritional care $[12,13]$.

We have recently reported the results from a randomized, controlled trial in acute stroke patients more than 65 years at nutritional risk, and we observed that an individualized energy- and protein supplementation during hospital stay improved health-related quality of life and grip strength after three months [14]. Notably, this intervention also reduced clinically relevant weight loss (i.e. $\geq 5 \%$ in three months) in the intervention group compared with the controls although statistical significance was not reached $(\mathrm{P}=0.055)$. Maintaining body weight is essential among acute stroke patients to prevent additional morbidity [11]. In order to achieve weight control and maintain energy- and protein status, it is important to understand how nutritional intervention affects body composition. Moreover, simple, quick and non-invasive methods for nutritional assessment are essential for monitoring nutritional status.

Hence, we examined the alterations in body composition using anthropometric measurements and bioelectrical impedance analysis in patients given individualized, nutritional support compared with those given routine care in our randomized trial. Gender-specific analyses were performed. We also examined the correlation between the different methods for assessing body-, fatand fat-free mass.

\section{Methods}

Inclusion process

Between May 2005 and December 2007 stroke patients were consecutively enrolled from the medical acute care ward at Østfold Hospital Trust to which acute stroke patients more than 65 years in Østfold County, Southeastern Norway were referred. The initial choice of antithrombotic treatment in patients with ischemic stroke was acetylsalicylic acid. All patients underwent computer tomography scanning or magnetic resonance imaging. Those with ischemic stroke or cerebral haemorrhage were eligible for nutritional risk assessment. The patient was excluded from study entry either if the stroke diagnosis could not be confirmed or if the patient was critically ill, had severe dementia, could not be weighed or if there was planned discharge within 24 hours after the first visit by the trial assessor. Nutritional risk status was assessed within seven days after admission using the Malnutrition Universal Screening Tool (MUST) [15] with minor modifications adjusted for elderly patients, i.e. the cut-off value for body mass index (BMI) was set at $\leq 20 \mathrm{~kg} / \mathrm{m}^{2}$. A marker of nutritional risk was either $\mathrm{BMI} \leq 20 \mathrm{~kg} / \mathrm{m}^{2}$, or unintentional weight loss of $\geq 5 \%$ the previous 3-6 months, or poor nutritional intake for at least five days, or the risk of inadequate nutritional intake for the next five days. Patients with at least one marker of nutritional risk present were included.

The inclusion process, sample size estimation and the randomization process is described in detail elsewhere [14]. In brief, we assessed 344 acute stroke patients with the MUST; 186 patients were at nutritional risk of which 16 refused to participate. We finally randomized 170 patients, and excluded three in the intervention group (not able to weigh $(\mathrm{n}=1)$, non-stroke $(\mathrm{n}=1)$ and withdrawn $(\mathrm{n}=1)$ ) and two in the control group (not able to weigh $(\mathrm{n}=1)$ and withdrawn $(\mathrm{n}=1)$ ) after randomization. The remaining 165 patients were randomized median 3 (range 1-6) days after hospital admission (i.e. baseline) to either individual, nutritional treatment or routine care. After median 93 days (range 67-133 days) (i.e. three month follow-up) 124 patients were reassessed and completed the study. Twenty-two patients died and 19 patients refused to attend three month follow-up. Among those which completed the study, 91 had been reassessed median 8 days (range 316 days) (i.e. week 1 ) after study entry. Informed consent was obtained from all patients. If the patient was unable to give written consent due to impaired functional ability, a third person (from the family or nursing staff) was asked to confirm the patient's consent.

Sample power calculations, based on the intention to reduce the percentage of patients becoming undernourished ( $\geq 5 \%$ weight loss) from 30 to 10 [16], showed that 124 patients in total were required. The patients were randomized to individualized, nutritional treatment (intervention) or to routine care (control) using sequentially numbered envelopes containing the name of the allocated study group. The sequence of treatment allocation was prepared from a computer-generated randomisation list by a person not involved in patient assessments.

The study protocol was approved by The Regional Committee for Medical and Health Research Ethics, Health Region South of Norway. This study is registered with ClinicalTrials.gov, number NCT00163007.

\section{Intervention}

The main treatment goal in the intervention group was to maintain or improve body weight during hospital stay. Nutritional treatment given was energy- and protein enriched meals, or established oral energy- and protein rich sip feedings (with $0.8-1.5 \mathrm{kcal}$ and $0.04-0.1 \mathrm{~g}$ protein per $\mathrm{mL}$ ), or enteral tube feeding (with $1.0 \mathrm{kcal}$ and $4.0 \mathrm{kcal}$ per $\mathrm{mL}$ ) according to the estimated individual nutritional intake and nutritional needs calculated 
according to the Schofield equations [17]. Dietary recording and the intervention are described in detail elsewhere [14]. In brief, dietary intake was recorded by the nursing staff using standardized dietary registration forms. An individual, nutritional treatment plan was prepared for each patient describing type, amount and route of feeding. Energy- and protein enriched meals were given and oral sip feedings were prescribed on the medicine chart to 47 patients, and tube feeding was offered to a total of 11 patients with severe dysphagia. The patients in the intervention group were discharged with nutritional advice given by a dietitian to prevent undernutrition.

The nutritional management in the control group conformed to routine practice, i.e. with no further assessment of nutritional intake or needs and treated without an individualized nutritional plan. The patients were reviewed after one week if they still were in hospital and then three months after study entry. They were not contacted before the three month follow-up.

\section{Body composition analyses}

Weight was measured on an electronic chair scale (SECA, Germany) to the nearest $0.1 \mathrm{~kg}$. Height was estimated from the knee-heel length using the age and gender specific equations from Chumlea et al [18]. Multifrequency bioelectrical impedance spectroscopy (BIS) (Bodyscout, Fresenius, Germany) was used to determine extracellular water $(\mathrm{ECW})$ and intracellular water (ICW) and to estimate fat mass, fat-free mass, lean tissue mass and body cell mass. The measurement was undertaken according to the manual for the BIS device. The patient had to remove all metal from the clothing and body, and be in a supine position for at least 10 minutes, and fasting for two hours, and not be engaged in heavy activity prior to the measurement. Patients with cardiac pacemakers or metallic stents were excluded from this measurement. Electrodes were attached to specified positions on the dorsal surface of the hand and the foot, either on the dominant or nonparetic side. During the measurement the patient was in a supine position with the arms and legs abducted from the body and instructed not to move or speak. Bioelectrical impedance analysis was not performed in $27 \%$ of the patients because of the exclusion criteria for the procedure, e.g. having a pacemaker. Mid upper arm circumference (MUAC) was measured with a tape measurer from the midpoint on the triceps on the dominant or non-paretic arm between the acromion and the olecranon processes. Triceps skinfold thickness (TSF) was measured at the midpoint with a skinfold caliper (Harpenden, Baty International, England) to the nearest 0.2 $\mathrm{cm}$. We used the average of three measurements. Arm muscle circumference (AMC) was estimated from the formula: MUAC - $(0.314 \times$ TSF $)$.

All clinical assessments were performed by one of two trial assessors. There were written procedures to standardise the measurements. The assessors were not blinded to which treatment the patient was assigned at study entry. To minimize the possible bias from not blinding at baseline, the information about the allocated treatment was made inaccessible to the assessor at three month follow-up.

\section{Statistical analyses}

Between-group comparison for continuous variables was evaluated with Student's t test or Mann-Whitney $U$ test. Normality was evaluated by the shape of the frequency histogram, normal Q-Q plot and Kalmogorov-Smirnov test. Comparison of weight change between the study groups was adjusted for baseline weight using a multiple regression analysis, and similar analysis were performed with BMI change. Within-group changes were compared with paired $t$-tests. The association between continuous variables is presented with Pearson's correlation coefficient $r$. Receiver operating characteristic (ROC) curve analysis was used to evaluate the accuracy of MUAC as a test to distinguish between BMI below or above a defined cut-off value. A P value $<0.05$ was considered statistically significant. Statistical analyses was performed with the software package SPSS (version 16, SPSS Inc. Chicago, IL, USA).

\section{Results}

The baseline characteristics in the study groups are shown in Table 1. The mean age was 79 years in those who completed the study, and there was no significant difference in age, percentage males and females, neurological status (Scandinavian Stroke Scale) or functional status (Barthel Index) between the two study groups. When we compared men and women, the baseline data did not significantly differ, except for age and prevalence of diabetes. The mean age in the men was significantly lower than in the women ( 77.3 vs 80.8 years), and there was significantly more diabetes in the men compared with the women (32\% vs $19 \%)$. Both the energy $(P=0.005)$ and protein $(P=0.001)$ intake after one week's intervention was significantly higher in the female intervention group compared with the female controls (Table 2). In the males, energy and protein intake did not differ significantly between those in the intervention group and the controls.

\section{Changes in body composition assessed with bioelectrical impedance}

The baseline values of body composition in both the male study groups and the female study groups were 
Table 1 Baseline characteristics of the two study groups

\begin{tabular}{lrr}
\hline & Control (n= 66) & Intervention (n= 58) \\
\hline Age, mean (SD) years & $79.7(6.8)$ & $78.5(7.4)$ \\
Males, number (\%), females, number (\%) & $35(53), 31(47)$ & $25(43), 33(57)$ \\
Cerebral haemorrhage, number (\%) & $8(12.1)$ & $4(6.9)$ \\
Scandinavian Stroke Scale, median score (range) & $42(7-58)$ & $41(6-58)$ \\
Barthel index, median score (range) & $11(0-20)$ & $11(0-20)$ \\
Smoker,\% & 19 & 17.2 \\
Diabetes,\% & 24.2 & 25.9 \\
Albumin, mean (SD) g/L & $39.1(3.8)$ & $39.5(3.0)$ \\
Transferrin, mean (SD) g/L & $2.1(0.4)$ & $2.2(0.5)$ \\
\hline
\end{tabular}

There were no significant differences in baseline values between the study groups.

similar (Table 3). Both the female control group and the female intervention group had a mean fat loss of $3.6 \mathrm{~kg}$ $(\mathrm{P}<0.001)$ and $1.4 \mathrm{~kg}(\mathrm{P}=0.005)$, respectively, which corresponded to $12.3 \%$ and $6.2 \%$ fat loss. The loss of fat mass was higher in the female control group compared with the female intervention group $(\mathrm{P}=0.005)$. The mean fat loss was significant within both male study groups; $2.9 \mathrm{~kg}(\mathrm{P}<0.001)$ in the controls and $3.2 \mathrm{~kg}$ $(\mathrm{P}=0.001)$ in the intervention group, but it did not differ between the study groups.

\section{Changes in anthropometry}

Figure 1 shows the changes in weight, BMI, MUAC, TSF and $\mathrm{AMC}$ after one week of intervention. One week after baseline the weight loss in the control group was significantly higher than in the intervention group $(P=0.013)$.

The baseline values and the changes after three months in anthropometry among men and women are presented in Table 4. Among the women the weight loss was significantly higher in the controls compared with the intervention group $(P=0.022)$. As for the men the mean weight loss was significant within both study groups, but was not different between the study groups. There was a significant decrease in TSF in both the male and female study groups, and this confirms that fat mass was decreased, but the change in TSF did not differ significantly between the study groups.

\section{Correlation between baseline anthropometry and bioelectrical impedance}

For both genders pooled TSF correlated well with fat mass $(\mathrm{r}=0.68, \mathrm{P}<0.001)$, and AMC correlated well with fat-free mass $(\mathrm{r}=0.68, \mathrm{P}<0.001)$, at baseline. Hence, there was a high correlation between body composition assessed with anthropometry and bioelectrical impedance. Moreover, there was a strong correlation between MUAC and BMI $(r=0.87, \mathrm{P}<0.001)$ for both genders pooled. The corresponding correlation for men and women analyzed separately, was $\mathrm{r}=0.88(\mathrm{P}<$ $0.001)$ and $r=0.91(P<0.001)$, respectively (Figure 2$)$.

\section{The association between MUAC and BMI}

We observed that MUAC was significantly associated with BMI independent of age and sex $(\mathrm{P}<0.001)$. Given the high correlation $(\mathrm{r}=0.87)$ between baseline MUAC and $\mathrm{BMI}$, we wanted to explore if MUAC could be used as a test to distinguish between those with BMI $\leq 20 \mathrm{~kg} / \mathrm{m}^{2}$ $(\mathrm{n}=21)$ and those with BMI $>20 \mathrm{~kg} / \mathrm{m}^{2}(\mathrm{n}=136)$. Sensitivity was plotted against 1-specificity for each measured value of MUAC generating a receiver operating characteristic (ROC) curve (Figure 3). The area under the ROC curve was 0.95 (95\% CI 0.92 to 0.99 ) implying a high accuracy of the test. A cut-off value for MUAC was chosen to maximize the sensitivity and the specificity of the test. Therefore MUAC $\leq 25.5 \mathrm{~cm}$ was set to detect BMI $\leq 20 \mathrm{~kg} / \mathrm{m}^{2}$ (i.e. positive test) and MUAC > 25.5. cm was set to detect BMI $>20 \mathrm{~kg} / \mathrm{m}^{2}$ (i.e. negative test). Sensitivity, specificity, and positive predictive value (PPV) and negative predictive value (NPV) of the test were $0.91,0.90$, 0.59 and 0.98 , respectively (Table 5 ). Consequently $91 \%$ of the patients with a BMI $\leq 20 \mathrm{~kg} / \mathrm{m}^{2}$ had a positive MUAC test and $90 \%$ of those with BMI $>20 \mathrm{~kg} / \mathrm{m}^{2}$ had a negative MUAC test. Among those with a positive MUAC test, $59 \%$ were placed in the correct BMI category, and the

Table 2 Energy and protein intake during the first week after study entry in the male and the female study groups

\begin{tabular}{lrrrrr}
\hline & Men & & & Women & \\
& Control & Intervention & $\mathbf{P}$ & Control & Intervention \\
\hline Energy $(\mathrm{kJ} / \mathrm{kg})$ & $69(21)$ & $76(26)$ & 0.34 & $59.7(19.0)$ & $83.2(31.3)$ \\
Protein $(\mathrm{g} / \mathrm{kg})$ & $0.79(0.28)$ & $0.78(0.27)$ & 0.87 & $0.65(0.23)$ & 0.005 \\
\hline
\end{tabular}

Data are presented as mean (SD) intake per kg body weight. 
Table 3 Baseline values and changes after three months in bioelectrical impedance analysis of body composition in the male and the female study groups

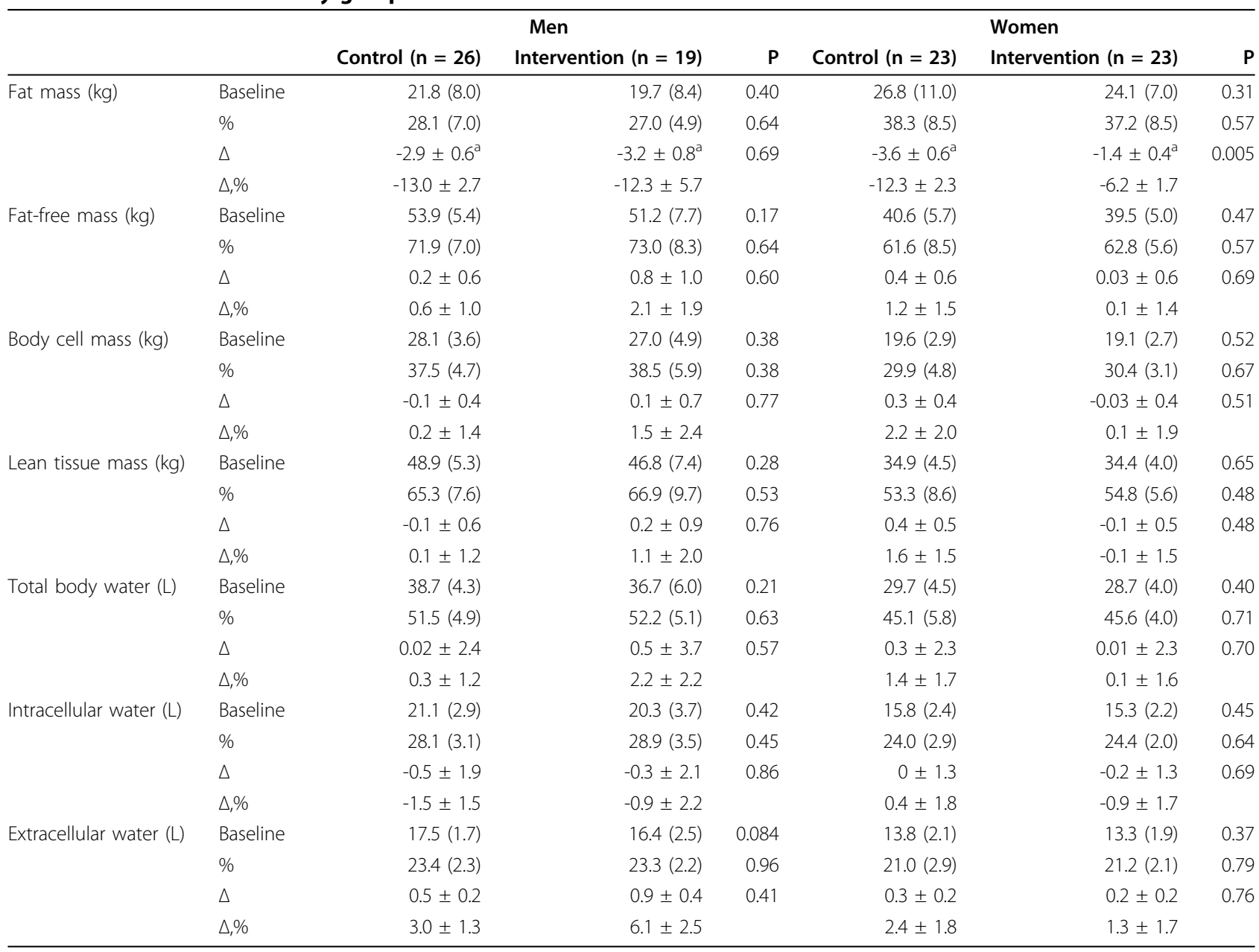

Baseline values are presented as mean (SD). Change is presented as mean \pm SEM. According to the manual of the BIS device "fat-free mass" comprises bone, skin, organs, blood, muscles, excess fluid and adipose water, "fat mass" comprises adipose lipids and essential lipids, "lean tissue mass" comprises bone, skin, organs, blood and muscles and "body cell mass" comprises skin, organs, blood and muscles. $\Delta$ : change from baseline to three months. ${ }^{a}$ Significant change within the group.

corresponding number in those with a negative MUAC test was $98 \%$. Among the 13 patients with a false positive MUAC test, seven had a BMI ranging from 20.2 to $21.0 \mathrm{~kg} / \mathrm{m}^{2}$.

A gender-specific analysis showed that a positive MUAC test set at $\leq 25.5 \mathrm{~cm}$ would give a low PPV of 0.52 in women and a high PPV of 0.73 in men (Table 5). If a positive MUAC test was set at $\leq 22.6 \mathrm{~cm}$ for women the PPV would increase to 0.77 and sensitivity, specificity and NPV would remain high.

\section{Discussion and Conclusions}

This study has shown that in older acute stroke patients at nutritional risk which received individualized nutritional support during hospital stay, the loss of body weight was reduced after one week compared with control patients who received only routine, nutritional care.
After three months the loss of body weight and fat mass was significant in both study groups, and in both men and women. However, the female intervention group had a significantly smaller loss of weight and fat mass compared with the female control group. This was not observed among the men. The estimation of fat and fatfree mass correlated well between bioelectrical impedance analysis and anthropometry.

We have previously shown that the intake of energy was $14 \%$ higher and significantly increased in the intervention group compared with the control group while in hospital [14], which could explain the better weight control after one week in the intervention group. Resting energy expenditure measured with indirect calorimetry after stroke was $88 \mathrm{~kJ}$ per $\mathrm{kg}$ body weight [19], and in immobile older patients, $84 \mathrm{~kJ}$ per $\mathrm{kg}$ body weight can be used to estimate the resting energy expenditure 


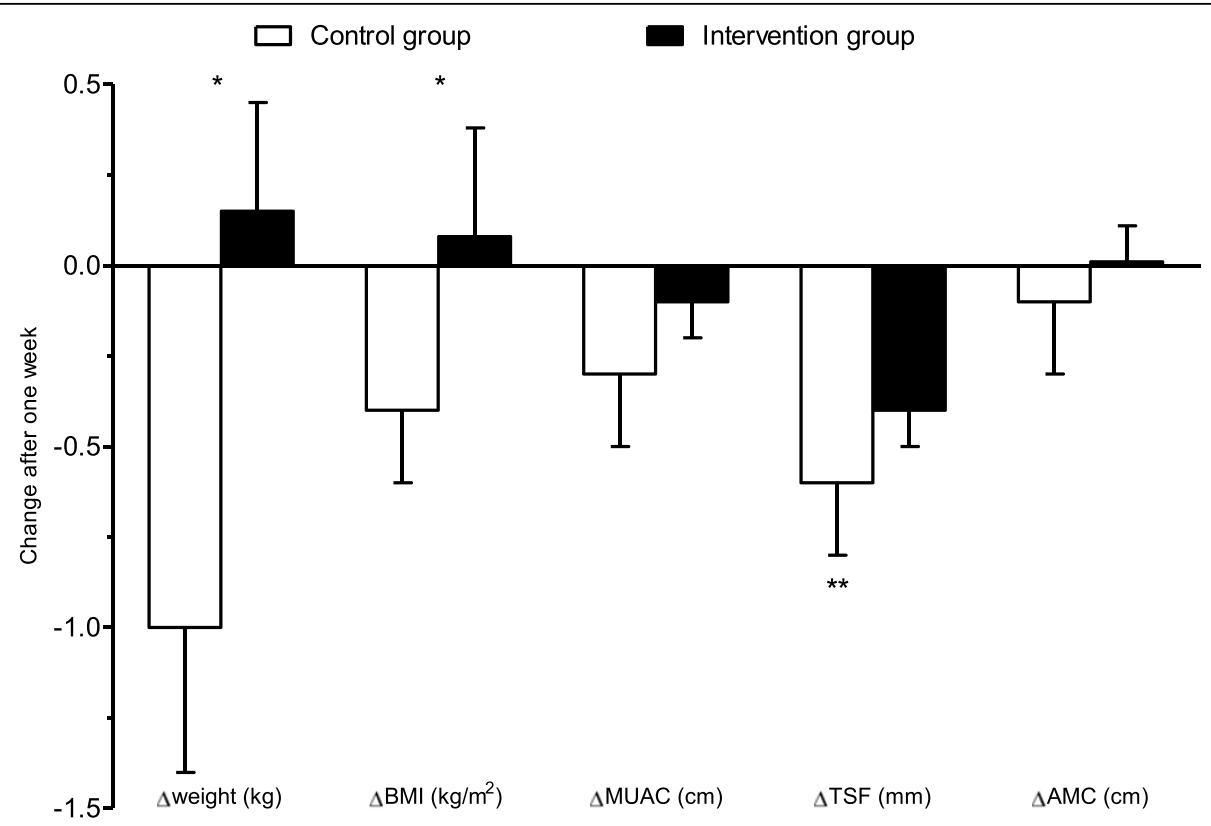

Figure 1 Change (mean \pm SEM) in anthropometry during the first week after study inclusion in the study groups. $\triangle$ : Change. *Significantly different between the groups; ** Significant change from baseline.

[20]. However, only the female intervention group in our study managed to reach a mean intake of $83 \mathrm{~kJ}$ and $0.9 \mathrm{~g}$ protein per $\mathrm{kg}$ body weight during hospital stay and was significantly higher than in the control group. Neither male study groups managed to achieve an energy intake above $80 \mathrm{~kJ}$ per $\mathrm{kg}$ body weight, and the intake did not differ between the groups. The lean tissue mass in men was $12 \mathrm{~kg}$ higher than in women, and it might have been more difficult for men to consume sufficient energy because the metabolic needs were higher. The higher prevalence of diabetes in the men compared with the women could possibly result in lower intake of food and drinks with added sugar, and hence, in the total intake of energy. Although we do not have data of the nutritional intake after hospital discharge, we observed that the women in the intervention group had a smaller loss of fat mass than the controls after three months indicating that the nutritional intake

Table 4 Baseline values and changes in anthropometry after three months in the male and the female study groups

\begin{tabular}{|c|c|c|c|c|c|c|c|}
\hline & & \multicolumn{3}{|c|}{ Men } & \multicolumn{3}{|c|}{ Women } \\
\hline & & Control $(n=35)$ & Intervention $(n=25)$ & $\mathbf{P}$ & Control $(n=31)$ & Intervention $(n=33)$ & $\mathbf{P}$ \\
\hline \multirow[t]{3}{*}{ Weight (kg) } & Baseline & $76.4(12.9)$ & $72.4(13.3)$ & 0.25 & $68.3(15.8)$ & $61.7(12.0)$ & 0.061 \\
\hline & $\Delta$ & $-2.5 \pm 0.7^{a}$ & $-2.0 \pm 0.8^{a}$ & 0.66 & $-2.9 \pm 0.7^{a}$ & $-0.8 \pm 0.6$ & 0.022 \\
\hline & $\Delta, \%$ & $-2.9 \pm 0.9$ & $-2.6 \pm 1.0$ & & $-4.2 \pm 1.0$ & $-1.1 \pm 1.0$ & \\
\hline \multirow[t]{3}{*}{$\mathrm{BMI}\left(\mathrm{kg} / \mathrm{m}^{2}\right)$} & Baseline & $25.3(3.7)$ & $24.5(3.8)$ & 0.42 & $27.2(5.3)$ & $24.5(4.1)$ & 0.026 \\
\hline & $\Delta$ & $-0.9 \pm 0.2^{\mathrm{a}}$ & $-0.8 \pm 0.3^{\mathrm{a}}$ & 0.84 & $-1.2 \pm 0.3$ & $-0.3 \pm 0.2$ & $0.052^{b}$ \\
\hline & $\Delta, \%$ & $-3.0 \pm 0.9$ & $-2.9 \pm 1.0$ & & $-4.2 \pm 1.0$ & $-1.1 \pm 1.0$ & \\
\hline \multirow[t]{3}{*}{ MUAC (cm) } & Baseline & $29.8(2.9)$ & $30.1(3.0)$ & 0.71 & $29.6(4.7)$ & $27.7(4.2)$ & 0.094 \\
\hline & $\Delta$ & $-0.8 \pm 0.2^{\mathrm{a}}$ & $-1.0 \pm 0.4^{\mathrm{a}}$ & 0.56 & $-0.8 \pm 0.3^{\mathrm{a}}$ & $-0.3 \pm 0.2$ & 0.14 \\
\hline & $\Delta, \%$ & $-2.5 \pm 0.7$ & $-3.2 \pm 1.1$ & & $-2.5 \pm 1.1$ & $-0.8 \pm 0.8$ & \\
\hline \multirow[t]{3}{*}{ TSF $(m m)$} & Baseline & $11.8(3.5)$ & $11.8(3.4)$ & 0.99 & $18.0(7.2)$ & $16.4(5.4)$ & 0.33 \\
\hline & $\Delta$ & $-0.9 \pm 0.3^{\mathrm{a}}$ & $-0.9 \pm 0.4^{\mathrm{a}}$ & 0.89 & $-1.6 \pm 0.6^{\mathrm{a}}$ & $-1.1 \pm 0.5^{\mathrm{a}}$ & 0.47 \\
\hline & $\Delta, \%$ & $-6.0 \pm 2.6$ & $-6.0 \pm 3.2$ & & $-5.8 \pm 3.7$ & $-4.8 \pm 2.7$ & \\
\hline \multirow[t]{3}{*}{$\mathrm{AMC}(\mathrm{cm})$} & Baseline & $26.1(2.3)$ & $26.4(2.5)$ & 0.63 & $23.9(3.1)$ & $22.5(3.0)$ & 0.069 \\
\hline & $\Delta$ & $-0.5 \pm 0.2^{a}$ & $-0.7 \pm 0.3^{a}$ & 0.52 & $-0.3 \pm 0.3$ & $0.1 \pm 0.2$ & 0.23 \\
\hline & $\Delta, \%$ & $-1.9 \pm 0.7$ & $-2.6 \pm 1.0$ & & $-1.2 \pm 1.1$ & $0.4 \pm 0.9$ & \\
\hline
\end{tabular}

Baseline values are presented as mean (SD). Change is presented as mean \pm SEM. $\Delta$ : change from baseline to three months. ${ }^{\text {a }}$ Significant change within the group; ${ }^{b}$ Adjusted for baseline BMI. 


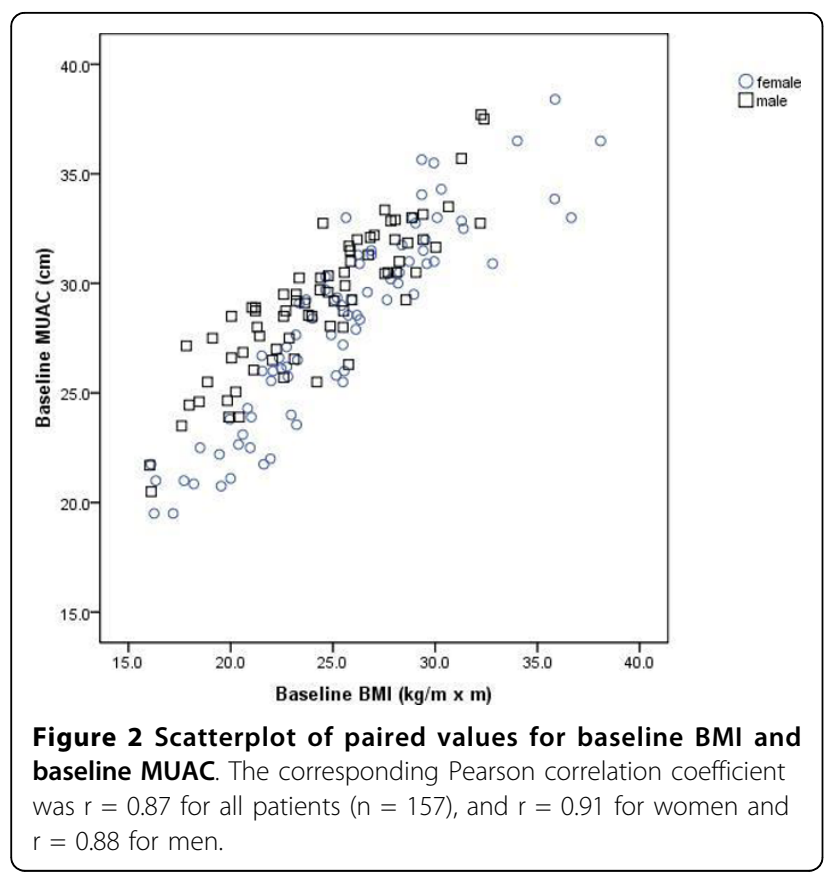

remained better in the female intervention group. This could have been attributed to the improved nutritional intake during hospital stay and the nutritional advice given before hospital discharge. In our study there were minor and non-significant increases in whole-body fatfree mass, body cell mass and lean tissue mass after three months in both genders and in both study groups.

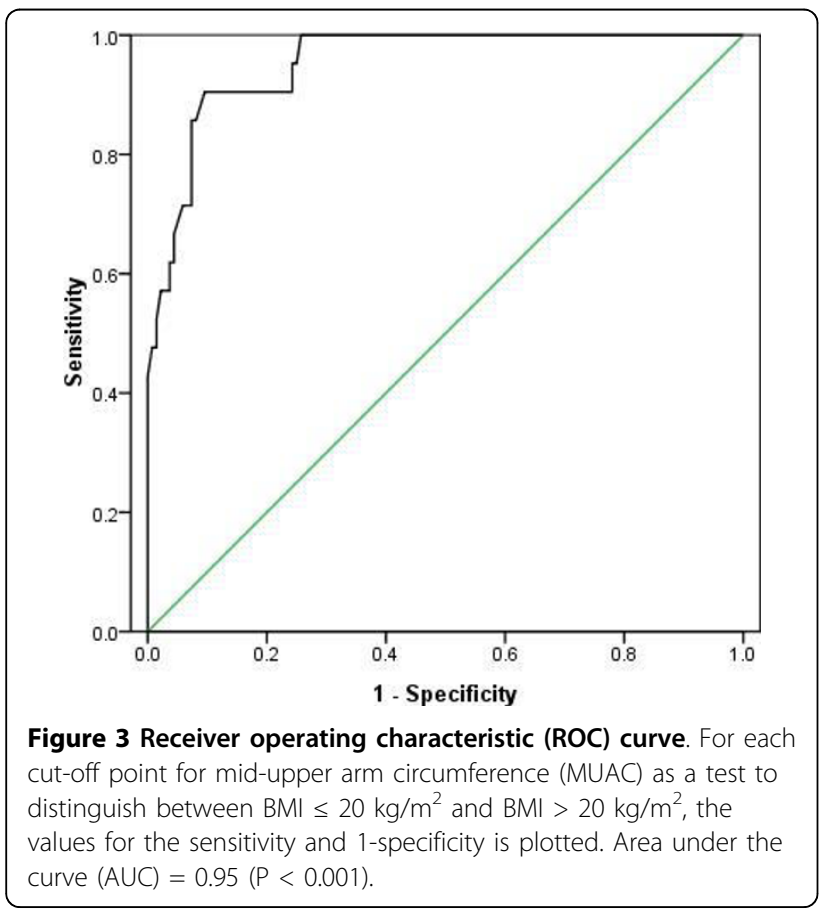

A loss of muscle mass has been shown with dual-energy X-ray absorptiometry (DXA) in both the paretic leg and the non-paretic in stroke patients who had not relearned to walk after two months, and after one year the lean mass in the non-paretic leg was regained [21]. In a study with 11 stroke patients there were no significant change over time in the muscle mass of the arms or legs [22].

In our study population mean baseline fat-free mass level was between the $25^{\text {th }}$ and $50^{\text {th }}$ percentile, and fat mass level between the $50^{\text {th }}$ and the $75^{\text {th }}$ percentile based on reference values adjusted for age and gender from a cohort of Swedish elderly [23]. Fat mass is lower and fat-free mass higher in men than in women, and fat mass naturally increases with age. Metabolic needs does not seem to be increased after an acute stroke [24]. However, feeding difficulties is not uncommon after an acute stroke [2] and may result in inadequate nutritional intake. Thus, the depletion of body fat as shown with both bioelectrical impedance analysis and with skinfold measurements in our study patients after three months, might have been related to partial starvation. During simple starvation glycogen reserves in the liver are quickly depleted during the first 24 hours of fasting. Muscle amino acids are mobilised and converted to glucose in the liver. However, muscle protein cannot continue to provide glucose substrates if fasting is prolonged for more than a few days, because the body would soon be depleted of essential proteins [25]. The mobilisation of free fatty acids (FFA) from adipose tissue is increased. When FFA are released from fat tissue to meet the energy needs of muscle tissue, this eventually leads to weight loss.

A low BMI is a marker of nutritional risk, and BMI is included in all nutritional screening tools recommended by the European Society for Parenteral and Enteral Nutrition (ESPEN) [26] to detect patients who could benefit from nutritional treatment. In clinical practice it requires more resources and time to weigh stroke patients who are bedridden compared with more ablebodied patients. Taking into account that is it more challenging to obtain weight and height in immobile patients, a measure of BMI may not be obtainable. We found a strong correlation $(r=0.87)$ between MUAC and BMI. With a cut-off point for MUAC at $25.5 \mathrm{~cm}$, $80 \%$ and $96 \%$ of the men would be correctly categorized as underweight or not underweight, respectively. Among men with a positive MUAC test $73 \%$ would be underweight and $97 \%$ of those with a negative MUAC test would be not underweight. For women a positive test set at MUAC $\leq 22.6 \mathrm{~cm}$ would give the corresponding numbers of $91 \%, 96 \%, 77 \%$ and $99 \%$. By using such a "MUAC for BMI test", more stroke patients could be assessed for nutritional risk in clinical practice. 
Table 5 The accuracy of the "MUAC test" to distinguish between BMI $\leq 20 \mathrm{~kg} / \mathrm{m}^{2}$ and BMI $>20 \mathrm{~kg} / \mathrm{m}^{2}$

\begin{tabular}{lrrrrr}
\hline & MUAC cut-off & Sensitivity $(\mathbf{9 5} \% \mathbf{C l})$ & Specificity (95\% Cl) & PPV (95\% Cl) & NPV (95\% Cl) \\
\hline Both men and women & $25.5 \mathrm{~cm}$ & $0.91(0.84-0.97)$ & $0.90(0.86-0.95)$ & $0.59(0.52-0.67)$ & $0.98(0.96-1.0)$ \\
Women & $25.5 \mathrm{~cm}$ & 1.0 & $0.86(0.80-0.91)$ & $0.52(0.45-0.60)$ & 1.0 \\
Women & $22.6 \mathrm{~cm}$ & $0.91(0.85-0.97)$ & $0.96(0.91-1.0)$ & $0.77(0.68-0.86)$ & $0.99(0.96-1.0)$ \\
Men & $25.5 \mathrm{~cm}$ & $0.80(0.74-0.86)$ & $0.96(0.92-0.99)$ & $0.73(0.66-0.80)$ & $0.97(0.94-1.0)$ \\
Men & $27.3 \mathrm{~cm}$ & $0.90(0.83-0.97)$ & $0.83(0.75-0.92)$ & $0.45(-0.07-0.56)$ & $0.98(0.94-1.0)$ \\
\hline
\end{tabular}

MUAC: mid-upper arm circumference; PPV: positive predictive value; NPV: negative predictive value.

However, the validity of using MUAC to identify those patients which would benefit from nutritional treatment, needs to be confirmed in larger studies.

The study groups were well-balanced for most variables at baseline except for weight and BMI. Thus, when we compared changes in weight and BMI in the groups, the data analyses were adjusted for the respective baseline values. The patients in the intervention group with missing bioelectrical impedance data were relatively younger and weighed less. The mortality rate was $13 \%$, and $12 \%$ of the patients did not participate in follow-up after three months, which is considerably lower than the reported loss to follow-up of $21-54 \%$ of elderly subjects participating in non-pharmacological trials [27-30].

Bioelectrical impedance analysis provides a validated and relatively easy and non-invasive approach to assess body composition among elderly patients and with minimal discomfort [23,31-33]. Whole body BIA allows the determination of the fat-free mass and TBW in subjects without significant fluid or electrolyte abnormalities and when using established procedures [34]. The determination of body fluid volumes via bioelectrical impedance methods is based on the assumption that electrical current at low frequencies cannot penetrate cell membranes and thus flows through the ECW space only, while high frequency current flows through both the ECW and ICW spaces [35]. Disturbances in fluid distribution can give errors in body fluid analyses and therefore in the estimation of fat and fat-free mass [32]. The TBW and ECW measured by BIS have been validated against reference methods $\left(\mathrm{D}_{2} \mathrm{O}\right.$ dilution and $\mathrm{NaBr}$ dilution method, respectively) with good accuracy, in both healthy subjects and in patients with imbalanced fluid status [35]. Fat-free mass and fat mass estimates measured by a BIS device similar to the device used in our study have been validated against DXA estimates in a cohort of older subjects (average age 75 years). Average FFM measured by BIS was in agreement with DXA. However, there was a small systematic positive bias although a large individual variation was observed. Average fat mass measured by BIS was also in agreement with DXA, but with a small systematic negative bias [36]. However, there is a lack of validation studies in stroke patients specifically. To minimize potential errors associated with the bioelectrical impedance measurements, we provided standardised conditions (supine position, resting, fasting) for the measurements. Moreover, since we were mainly interested in the relative change in body composition among the individual patients during the three months observation period, any measurement error is less likely to alter our findings.

In summary, this study suggests that body composition is less negatively affected in older stroke patients receiving individualized nutritional support during hospital stay compared with routine, nutritional care. There is a deterioration in nutritional status after hospital discharge. Among women this nutritional intervention strategy reduced the catabolic process after three months. Measurement of MUAC may be used in assessment of nutritional status when BMI cannot be obtained. In older stroke patients at nutritional risk, we recommend regular assessment of dietary intake and nutritional status after hospital discharge as a part of follow-up in local health care.

\section{Acknowledgements}

This study was supported by the South-Eastern Norway Regional Health Authority and Østfold Hospital Trust. The funding sources had no influence on the data analyses or the writing of the manuscript or the decision to submit. The authors thank the participating patients, the multidisciplinary stroke team at Medisin 2, Østfold Hospital Trust, Moss, and Leiv Sandvik for assisting us in use of statistical methods.

\section{Author details}

Department of Internal Medicine, Østfold Hospital Trust Fredrikstad, 1603 Fredrikstad, Norway. ${ }^{2}$ Department of Gastroenterology, Oslo University Hospital, Ullevål, 0407 Oslo, Norway. ${ }^{3}$ Department of Nutrition, Institute of Basic Medical Sciences, PO Box 1046 Blindern, University of Oslo, 0316 Oslo, Norway. ${ }^{4}$ Department of Hematology, Oslo University Hospital, Ullevål, 0407 Oslo, Norway.

\section{Authors' contributions}

$\mathrm{LH}$ participated in the development and design of the study, conducted and supervised assessments and procedures within the study, had full access to the complete set of data and drafted the manuscript. TH and POI contributed to the study design, reviewed and interpreted data and participated in writing of the manuscript. All authors have seen and approved the final version of the manuscript.

\section{Competing interests}

The authors declare that they have no competing interests. 
Received: 29 May 2010 Accepted: 18 October 2010

Published: 18 October 2010

\section{References}

1. Davalos A, Ricart W, Gonzalez-Huix F, Soler S, Marrugat J, Molins A, Suner R, Genis D: Effect of malnutrition after acute stroke on clinical outcome. Stroke 1996, 27(6):1028-1032.

2. Jonsson AC, Lindgren I, Norrving B, Lindgren A: Weight loss after stroke: a population-based study from the Lund Stroke Register. Stroke 2008, 39(3):918-923.

3. Axelsson K, Asplund K, Norberg A, Alafuzoff I: Nutritional status in patients with acute stroke. Acta Med Scand 1988, 224(3):217-224.

4. Axelsson K, Asplund K, Norberg A, Eriksson S: Eating problems and nutritional status during hospital stay of patients with severe stroke. $J$ Am Diet Assoc 1989, 89(8):1092-1096.

5. Unosson M, Ek AC, Bjurulf $P$, von Schenck H, Larsson J: Feeding dependence and nutritional status after acute stroke. Stroke 1994 25(2):366-371.

6. Brynningsen PK, Damsgaard EM, Husted SE: Improved nutritional status in elderly patients 6 months after stroke. J Nutr Health Aging 2007, 11(1):75-79.

7. Davis JP, Wong AA, Schluter PJ, Henderson RD, O'Sullivan JD, Read SJ: Impact of premorbid undernutrition on outcome in stroke patients. Stroke 2004, 35(8):1930-1934

8. Yoo SH, Kim JS, Kwon SU, Yun SC, Koh JY, Kang DW: Undernutrition as a predictor of poor clinical outcomes in acute ischemic stroke patients. Arch Neurol 2008, 65(1):39-43

9. Gariballa SE, Parker SG, Taub N, Castleden M: Nutritional status of hospitalized acute stroke patients. Br J Nutr 1998, 79(6):481-487.

10. FOOD Trial Collaboration: Poor nutritional status on admission predicts poor outcomes after stroke: observational data from the FOOD trial. Stroke 2003, 34(6):1450-1456.

11. Volkert D, Berner YN, Berry E, Cederholm T, Coti Bertrand P, Milne A Palmblad J, Schneider S, Sobotka L, Stanga Z, DGEM (German Society for Nutritional Medicine), Lenzen-Grossimlinghaus R, Krys U, Pirlich M, Herbst B, Schutz T, Schroer W, Weinrebe W, Ockenga J, Lochs H, ESPEN (European Society for Parenteral and Enteral Nutrition): ESPEN Guidelines on Enteral Nutrition: Geriatrics. Clin Nutr 2006, 25(2):330-360

12. Gariballa SE, Parker SG, Taub N, Castleden CM: A randomized, controlled, a single-blind trial of nutritional supplementation after acute stroke. JPEN J Parenter Enteral Nutr 1998, 22(5):315-319.

13. Rabadi MH, Coar PL, Lukin M, Lesser M, Blass JP: Intensive nutritional supplements can improve outcomes in stroke rehabilitation. Neurology 2008, 71(23):1856-1861.

14. Ha L, Hauge T, Spenning AB, Iversen PO: Individual, Nutritional Support Prevents Undernutrition, Increases Muscle Strength and Improves QoL among Elderly at Nutritional Risk Hospitalized for Acute Stroke: A Randomized, Controlled trial. Clin Nutr 2010, 29(5):567-573.

15. Stratton RJ, King CL, Stroud MA, Jackson AA, Elia M: 'Malnutrition Universal Screening Tool' predicts mortality and length of hospital stay in acutely ill elderly. Br J Nutr 2006, 95(2):325-330.

16. Lauque S, Arnaud-Battandier F, Gillette S, Plaze JM, Andrieu S, Cantet C, Vellas B: Improvement of weight and fat-free mass with oral nutritional supplementation in patients with Alzheimer's disease at risk of malnutrition: a prospective randomized study. J Am Geriatr Soc 2004, 52(10):1702-1707.

17. Schofield WN: Predicting basal metabolic rate, new standards and review of previous work. Hum Nutr Clin Nutr 1985, 39(Suppl 1):5-41.

18. Chumlea WC, Roche AF, Steinbaugh ML: Estimating stature from knee height for persons 60 to 90 years of age. J Am Geriatr Soc 1985, 33(2):116-120

19. Foley N, Finestone $H$, Woodbury MG, Teasell R, Greene Finestone L: Energy and protein intakes of acute stroke patients. J Nutr Health Aging 2006, 10(3):171-175.

20. Lammes $E$, Akner $G$ : Resting metabolic rate in elderly nursing home patients with multiple diagnoses. J Nutr Health Aging 2006, 10(4):263-270.

21. Jorgensen $\mathrm{L}$, Jacobsen BK: Changes in muscle mass, fat mass, and bone mineral content in the legs after stroke: a 1 year prospective study. Bone 2001, 28(6):655-659.
22. Carin-Levy G, Greig C, Young A, Lewis S, Hannan J, Mead G: Longitudinal changes in muscle strength and mass after acute stroke. Cerebrovasc Dis 2006, 21(3):201-207.

23. Dey DK, Bosaeus I, Lissner L, Steen B: Body composition estimated by bioelectrical impedance in the Swedish elderly. Development of population-based prediction equation and reference values of fat-free mass and body fat for 70- and 75-y olds. Eur J Clin Nutr 2003, 57(8):909-916

24. Finestone HM, Greene-Finestone LS, Foley NC, Woodbury MG: Measuring longitudinally the metabolic demands of stroke patients: resting energy expenditure is not elevated. Stroke 2003, 34(2):502-507.

25. Ralph A, Garrow JS, James WPT: Human nutrition and dietetics Edinburgh: Churchill Livingstone, 91993.

26. Kondrup J, Allison SP, Elia M, Vellas B, Plauth M, Educational and Clinical Practice Committee, European Society of Parenteral and Enteral Nutrition (ESPEN): ESPEN guidelines for nutrition screening 2002. Clin Nutr 2003, 22(4):415-421.

27. Price $R$, Daly F, Pennington CR, McMurdo ME: Nutritional supplementation of very old people at hospital discharge increases muscle strength: a randomised controlled trial. Gerontology 2005, 51(3):179-185.

28. Harari D, Norton C, Lockwood L, Swift C: Treatment of constipation and fecal incontinence in stroke patients: randomized controlled trial. Stroke 2004, 35(11):2549-2555.

29. Edington J, Barnes R, Bryan F, Dupree E, Frost G, Hickson M, Lancaster J, Mongia S, Smith J, Torrance A, West R, Pang F, Coles SJ: A prospective randomised controlled trial of nutritional supplementation in malnourished elderly in the community: clinical and health economic outcomes. Clin Nutr 2004, 23(2):195-204.

30. Carnaby G, Hankey GJ, Pizzi J: Behavioural intervention for dysphagia in acute stroke: a randomised controlled trial. Lancet Neurol 2006, 5(1):31-37.

31. Olde Rikkert MG, Deurenberg P, Jansen RW, van't Hof MA, Hoefnagels WH: Validation of multifrequency bioelectrical impedance analysis in monitoring fluid balance in healthy elderly subjects. J Gerontol A Biol Sci Med Sci 1997, 52(3):M137-41.

32. Kyle UG, Bosaeus I, De Lorenzo AD, Deurenberg P, Elia M, Manuel Gomez J, Lilienthal Heitmann B, Kent-Smith L, Melchior JC, Pirlich M, Scharfetter H, Schols AMWJ, Pichard C, ESPEN: Bioelectrical impedance analysis-part II: utilization in clinical practice. Clin Nutr 2004, 23(6):1430-1453.

33. Jaffrin MY, Morel H: Body fluid volumes measurements by impedance: $A$ review of bioimpedance spectroscopy (BIS) and bioimpedance analysis (BIA) methods. Med Eng Phys 2008, 30(10):1257-1269.

34. Kyle UG, Bosaeus I, De Lorenzo AD, Deurenberg P, Elia M, Gomez JM, Heitmann BL, Kent-Smith L, Melchior JC, Pirlich M, Scharfetter H, Schols AM, Pichard C, Composition of the ESPEN Working Group: Bioelectrical impedance analysis-part I: review of principles and methods. Clin Nutr 2004, 23(5):1226-1243.

35. Moissl UM, Wabel P, Chamney PW, Bosaeus I, Levin NW, Bosy-Westphal A Korth O, Muller MJ, Ellegard L, Malmros V, Kaitwatcharachai C, Kuhlmann MK, Zhu F, Fuller NJ: Body fluid volume determination via body composition spectroscopy in health and disease. Physiol Meas 2006, 27(9):921-933

36. Tengvall M, Ellegard L, Malmros V, Bosaeus N, Lissner L, Bosaeus I: Body composition in the elderly: reference values and bioelectrical impedance spectroscopy to predict total body skeletal muscle mass. Clin Nutr 2009, 28(1):52-58

\section{Pre-publication history}

The pre-publication history for this paper can be accessed here: http://www.biomedcentral.com/1471-2318/10/75/prepub

doi:10.1186/1471-2318-10-75

Cite this article as: Ha et al:: Body composition in older acute stroke patients after treatment with individualized, nutritiona supplementation while in hospital. BMC Geriatrics 2010 10:75. 